\title{
Inotropic effect of Citrus sinensis (L.) Osbeck leaf extracts on the guinea pig atrium
}

E.D. Oliveira ${ }^{1,2}$, T.S. Leite ${ }^{1}$, B.A. Silva ${ }^{2}$ and E.A. Conde-Garcia ${ }^{1}$

\author{
'Laboratório de Biofísica do Coração, Departamento de Fisiologia, \\ Centro de Ciências Biológicas e da Saúde, Universidade Federal de Sergipe, \\ Aracaju, SE, Brasil \\ ${ }^{2}$ Laboratorio de Tecnologia Farmacêutica, Universidade Federal da Paraíba, \\ João Pessoa, PB, Brasil
}

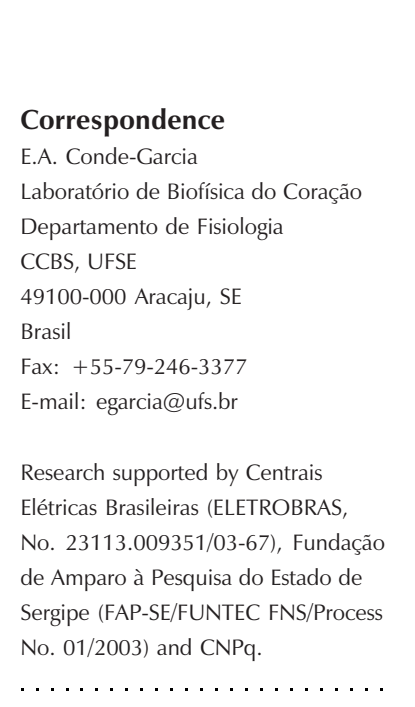

Received March 3, 2004 Accepted October 6, 2004

\begin{abstract}
The objective of the present investigation was to determine the contractile effect of crude and acetone leaf extracts of Citrus sinensis (L.) Osb. on mammalian myocardium. Crude leaf extracts have been used in folk medicine to treat neurological disorders. Some flavonoids isolated from this plant presented a positive inotropic effect on myocardium. This motivated us to test the extracts on the atria of guinea pigs of both sexes (300-500 g) and surprisingly we observed inotropic depression instead of an increase in force. The maximum effect of the crude extract was $79.4 \pm 8.1 \%$ of the control force amplitude $\left(\mathrm{N}=5\right.$ hearts, 10 trials, $27 \pm 0.1^{\circ} \mathrm{C}$, stimulus: $2 \mathrm{~Hz}, 400 \mathrm{~V}$, $0.5 \mathrm{~ms}$ ). The $\mathrm{EC}_{50}$ for crude, ethanol, acetic, aqueous, and acetone extracts was $300,300,600,1000$, and $140 \mu \mathrm{g} / \mathrm{ml}$, respectively, with a Hill constant of 1.8, 2.0, 2.5, 2.0, and 1.4, respectively. Blockade of cholinergic, beta-adrenergic, or opioid membrane receptors with 1.5 $\mu \mathrm{M}$ atropine sulfate, $1 \mu \mathrm{M}$ propranolol, and $10 \mu \mathrm{M}$ naloxone, respectively, did not change the effect of the crude extract. The acetone extract abolished the Bowditch positive staircase phenomenon $(\mathrm{N}=5$ hearts, 10 trials, $27 \pm 0.1^{\circ} \mathrm{C}$ ), suggesting a possible reduction of the calcium inward current, and also promoted the so-called Woodworth phenomenon. The effect was concentration-dependent and indicated the existence of another inhibitory contractile mechanism such as the simultaneous activation of some of the membrane potassium channels reducing the myocardial action potential duration and further decreasing the cellular calcium entry.
\end{abstract}

\section{Introduction}

Citrus sinensis (L.) Osb., hereafter referred to as $C$. sinensis, is a plant of the Rutaceae family native to Asia and India (1$3)$, which is widely cultivated all over the world. Its fruit, rich in vitamin $\mathrm{C}$, is consumed fresh or industrialized as juice and is
Key words

- Citrus sinensis

- Contractility

- Heart

- Myocardium

- Woodworth phenomenon of great economical importance. Different extracts obtained from the leaves and the peel of the fruit have been used to kill mosquito larvae and mites $(4,5)$, as antimicrobial agents (6), and as antifungal agents (7). Leaf extracts have been used in folk medicine to treat neurological disorders and to facilitate the digestion of food (8). 
Many substances have been isolated from C. sinensis leaves: glycosides (apigenin and diosmetin), ruteosides (luteolin), caffeine, hydroxyproline, flavonoids (natsudaidaine, HEPTA $(3,5,6,7,8,3$ ', 4'-hexamethoxyflavone), hesperidin, and diosmin), and the triterpene linomin (9-12). Hesperidin and diosmin have been shown to have anti-inflammatory, antihypertensive, diuretic, analgesic, and hypolipidemic properties (10). Natsudaidaine and HEPTA showed a positive inotropic effect on the guinea pig right ventricle (13). This cardiac effect motivated us to study the contractile action of $C$. sinensis extracts on the mammalian heart. However, when the crude water-alcohol extract was tested on the guinea pig atria, a marked depressant effect was observed instead of the positive one reported in the literature (13). This surprising result motivated us to investigate the effect of $C$. sinensis on myocardial contractility. In addition, it is well known that substances that depress the heart are commonly used as antiarrhythmic agents (i.e., verapamil). Thus, the present study can contribute to the elucidation of some characteristics of new active compounds that might be of importance in the future as pharmacological tools for the treatment of cardiac disorders. In spite of the wide use of $C$. sinensis, very little was found regarding its effects on the mammalian heart.

The aim of the present study was to characterize and report the negative inotropic effect produced by some of the $C$. sinensis extracts on the guinea pig left atrium.

\section{Material and Methods}

\section{Plant material}

C. sinensis leaves were collected in the town of Boquim (Sergipe, Brazil, 11 1 15' 15" $\mathrm{S}$ latitude, $37^{\circ} 33^{\prime} 45^{\prime \prime} \mathrm{W}$ longitude) from agrotoxic-free trees during the winter season. A botanical specimen was classified as Citrus aurantium L. var. sinensis Gall., which is another taxonomic way of referring to $C$. sinensis L. Osb. (14). A voucher specimen (No. 36,773) was deposited in the Herbarium of the Federal University of Pernambuco, Recife, PE, Brazil.

\section{Drugs}

The following drugs, diluted in water, were used: $1.5 \mu \mathrm{M}$ atropine sulfate, $0.7 \mu \mathrm{M}$ propranolol, $0.3 \mu \mathrm{M}$ acetylcholine chloride, $1 \mu \mathrm{M}$ epinephrine bitartrate, and $10 \mu \mathrm{M}$ naloxone. All drugs were purchased from Sigma-Aldrich (St. Louis, MO, USA) except for naloxone, which was from Rhodia Farma (São Paulo, SP, Brazil).

\section{Extract preparation}

A crude water-alcohol extract was obtained by macerating dry leaves in an ethanol and water solution $(6: 4, \mathrm{v} / \mathrm{v})$ maintained at $27 \pm 3^{\circ} \mathrm{C}$ for 10 days. The extract was concentrated in a rotary evaporator (Buchi RE 111; Buchi Laboratoriums-Tecnick AG, Flawil, Switzerland).

The hexane, chloroform, acetone, ethanol, methanol, and acetic acid extracts were prepared with a Soxhlet extractor using solvents of analytical grade purchased from VETEC (Rio de Janeiro, RJ, Brazil).

After removal of the solvent, the extracts were stored at $27 \pm 3^{\circ} \mathrm{C}$ in a dry atmosphere without any light protection and their $\mathrm{Na}^{+}$ and $\mathrm{K}^{+}$contents were determined by flame photometry using an Analyzer Model 900 (Analyser Comércio e Indústria Ltda., São Paulo, SP, Brazil).

\section{Experimental procedures}

The experimental procedures were previously approved by the Research Ethics Committee of the Federal University of Sergipe. The animals were handled according to usual procedures extensively described in the specialized literature, following the 
ethical rules disposed by the Brazilian College for Animal Experimentation (COBEA, Colégio Brasileiro de Experimentação Animal).

The experiments were carried out on the guinea pig left atria removed from animals of both sexes (300-500 g) killed by a blow to the skull base. The chest was opened and the heart promptly excised and transferred to an organ bath. The left atrium was immersed in a modified Tyrode solution consisting of $137 \mathrm{mM} \mathrm{NaCl}, 5.0 \mathrm{mM} \mathrm{KCl}, 0.5 \mathrm{mM} \mathrm{MgCl}_{2}$, $12.0 \mathrm{mM} \mathrm{NaHCO}_{3}, 1.8 \mathrm{mM} \mathrm{CaCl}_{2}, 6.0 \mathrm{mM}$ glucose, and $1.8 \mathrm{mM} \mathrm{NaH}_{2} \mathrm{PO}_{4}$, salts of analytical grade manufactured by and purchased from Merck S.A. Indústrias Químicas, Rio de Janeiro, RJ, Brazil. The bath was oxygenated and buffered with a carbogen mixture $\left(95 \% \mathrm{O}_{2}+5 \% \mathrm{CO}_{2}\right.$ purchased from either Aga S.A., São Paulo, SP, Brazil or White Martins Gases Industriais S.A., São Paulo, $\mathrm{SP}$, Brazil). The bath temperature was maintained at $27 \pm 0.1^{\circ} \mathrm{C}$ by means of a thermostatically controlled water jacket.

The atria were stretched to $10 \mathrm{mN}(1 \mathrm{gf}=$ $9.807 \mathrm{mN}$ ) as a control diastolic tension. Suprathreshold rectangular electrical pulses of $2 \mathrm{~Hz}, 400 \mathrm{~V}$, and $0.5 \mathrm{~ms}$, provided by a Programmer (4030) and a Stimulator (3072) manufactured by Digitimer Limited, Welwyn Garden City, Hertfordshire, England, were delivered by a pair of $\mathrm{Ag} / \mathrm{AgCl}$ electrodes placed inside the organ bath to pace the preparations. These electrodes were arranged along the atrium in order to provide a simultaneous excitation of the entire preparation (field stimulation). The myocardial force was recorded isometrically with a force transducer (HP FTA 10-1 Sunborn, HP 8805B, Chicago, IL, USA) with the aid of a thermal paper polygraph (HP 8805B, HP 7754A, HP 7754B). Data were also stored in a computer (512 samples/s; A/D converter DI-400, WINDAQ Proacquisition, DATAQ Instruments, Akron, OH, USA) for off-line processing. Before starting the experimental procedures, the atrium was allowed to stabilize for about $1 \mathrm{~h}$. The preparation was considered to be well adapted when its force amplitude and resting tension remained unchanged.

The extracts were added cumulatively to the organ bath and the experiments were carried out using the following concentration range: crude extract $(100-2000 \mu \mathrm{g} / \mathrm{ml})$, ethanol extract $(30-2500 \mu \mathrm{g} / \mathrm{ml})$, acetone extract (10-1200 $\mu \mathrm{g} / \mathrm{ml})$, aqueous extract (30$4000 \mu \mathrm{g} / \mathrm{ml}$ ), and acetic acid extract (30$2500 \mu \mathrm{g} / \mathrm{ml}$ ).

\section{Phytochemical screening}

Phytochemical screening was performed on the $C$. sinensis acetone extract according to the techniques proposed by Domínguez (15).

\section{Acute toxicity testing}

Twenty Mus musculus mice (10 males and 10 females weighing 23 to $33 \mathrm{~g}$ ) were studied after 7 days of acclimation. The animals were housed in groups of 5 in wide cages, with free access to water and commercial laboratory chow. They remained at room temperature $\left(27 \pm 2^{\circ} \mathrm{C}\right)$ under a natural 12-h light-dark cycle (from 5:30 to 17:30 h, approximately). Ten mice were randomly assigned to test groups of 5 males (23 to 26 $\mathrm{g}$ ) and 5 females ( 28 to $33 \mathrm{~g}$ ). The control group consisted of 5 males ( 24 to $27 \mathrm{~g}$ ) and 5 females (26 to $32 \mathrm{~g}$ ). Acute toxicity testing was performed by injecting intraperitoneally (ip) the male and female control group with $0.25 \pm 0.01$ and $0.30 \pm 0.02 \mathrm{ml}$ of saline, respectively, whereas the test groups received ip $2 \mathrm{~g} / \mathrm{kg}$ body weight of the $C$. sinensis extract. The injected volume was $0.25 \pm 0.01$ $\mathrm{ml}$ for males and $0.30 \pm 0.02 \mathrm{ml}$ for females. The animals remained under observation for 7 days after extract administration.

\section{Data processing}

Stored data were processed with the 
EG1v.1 software (Patent deposit No. 00051104, Instituto Nacional de Propriedade Industrial, INPI, Ministério do Desenvolvimento, Indústria e Comércio Exterior/ Brasília, DF, Brazil, also deposited in the Cartório do $10^{\circ}$ Ofício, Títulos e Documentos e Pessoas Jurídicas, Aracaju, SE, Brazil). To determine the effect of the extract on the guinea pig atrium contractility, the following variables were measured: a) atrial force maximum amplitude, b) atrial contraction time, c) atrial relaxation time, and d) atrial force derivatives related to the contraction and relaxation phases. Contraction time was measured at three different levels, i.e., 20, 50 , and $80 \%$ of the atrial force amplitude. A similar procedure was performed to determine the relaxation time. To obtain the mean value of each of these variables, 50 successive contractions were processed. These measurements were made during the following experimental phases: 1) control, 2) after adding the extract to the organ bath, and 3 ) after the washout recovery.

To determine the extract concentration required to produce $50 \%$ of the maximum extract effect $\left(\mathrm{EC}_{50}\right)$, the experimental data were fitted by curves calculated by the HillLangmuir equation (16-18):

$\mathrm{E}=\frac{\mathrm{E}_{\max }\left(\frac{\mathrm{C}}{\mathrm{EC}_{50}}\right)^{\mathrm{n}}}{1+\left(\frac{\mathrm{C}}{\mathrm{EC}_{50}}\right)^{\mathrm{n}}}$

where: $\mathrm{E}=$ effect of the extract on the contractile force amplitude; $\mathrm{E}_{\max }=$ maximum extract effect on the contractile force amplitude; $\mathrm{C}=$ extract concentration in the organ bath; $\mathrm{EC}_{50}=$ extract concentration producing $50 \%$ of the maximum effect, and $\mathrm{n}=$ Hill constant.

\section{Study of the inward calcium current}

The protocol of Nayler and Merrillees (19) was employed to study the effect of $C$. sinensis extracts $(1200 \mu \mathrm{g} / \mathrm{ml})$ on the membrane calcium inward current. The experiments were carried out on animals previously treated with $5 \mathrm{mg} / \mathrm{kg}$ reserpine (Gross Laboratory, Rio de Janeiro, RJ, Brazil) injected into the peritoneal cavity $24 \mathrm{~h}$ before the experiment. Reserpine was used to deplete the myocardial catecholamines and then to minimize extrasystole occurrence. The experimental protocol consisted of measuring the atrial force at different stimulation rates: 1$)$ low frequency $(0.2 \mathrm{~Hz}$, control rate), 2) high frequency $(0.33,0.5,0.66,1.0,1.33$, 1.66 , or $2.0 \mathrm{~Hz}, 40 \mathrm{~s}$ ), 3) silent period (no stimulation was applied for $40 \mathrm{~s}$ ), followed by 4$)$ low frequency $(0.2 \mathrm{~Hz})$. This cycle was performed when normal Tyrode (control solution) was used or after adding a $C$. sinensis extract to the organ bath (test solution). The Nayler and Merrillees (19) protocol is based on the Bowditch phenomenon (positive staircase) that appears when the stimulation rate is suddenly increased. In this paper, 'force overshoot' stands for the amount of force over the force amplitude observed during the control phase.

\section{Statistical analysis}

The Student $t$-test for independent samples was used to determine differences between means. Results were considered to be statistically different when $\mathrm{P}$ was less than 0.05 (Statistica for Windows). Data are reported as means $\pm \mathrm{SD}$.

\section{Results}

A sodium and potassium content equal to $0.013 \mathrm{mM}$ and $1.2 \mathrm{mM}$ was obtained by flame photometry for $1 \mathrm{~g} / 1$ of $C$. sinensis crude extract. The yields of solids for each of the $C$. sinensis extracts were: $16 \%(160 \mathrm{~g} / \mathrm{kg}$ dry leaves) for the crude water-alcohol extract and 3.4\% (34 g/ $\mathrm{kg}$ dry leaves) for the hexane extract, $2.05 \%(20.5 \mathrm{~g} / \mathrm{kg}$ dry leaves $)$ for the chloroform extract, $1.6 \%(16 \mathrm{~g} / \mathrm{kg}$ dry 
leaves) for the acetone extract, $1.2 \%(12 \mathrm{~g} /$ $\mathrm{kg}$ dry leaves) for the ethanol extract, $3.4 \%$ (34 g/kg dry leaves) for the methanol extract, $3.7 \%$ (37 g/kg dry leaves) for the aqueous extract, and $4.3 \%$ ( $43 \mathrm{~g} / \mathrm{kg}$ dry leaves) for the acetic acid extract.

The phytochemical screening of the acetone extract of $C$. sinensis revealed the following types of compounds: 1) saponin [foam (-)];2) alkaloid [Bouchardat (-), Mayer $(-)$, Dragendorff (-), tungstosilicic acid (-)]; 3) steroid [acetic anhydride plus sulfuric acid (+)]; 4) tannin [gelatin $0.5 \%(++), \mathrm{FeCl}_{3}$ $(++)$; 5) flavonoid [magnesium tape $(+++)$, fluorescence $(+++)]$.

Figure 1 shows the negative inotropic effect of the crude water-alcohol extract of C. sinensis with a concentration-dependent reduction in atrial force. Despite its relevant magnitude (79\%), this effect promptly disappeared when the extract was removed from the organ bath. Similar results were obtained in 10 trials carried out on 5 atria.

Experiments carried out to determine which solvent extract of $C$. sinensis had the most potent depressant effect are shown in Figure 2. Hill-Langmuir curves used to determine the $\mathrm{EC}_{50}$ of different extracts indicated $\mathrm{EC}_{50}$ values equal to $300,300,600$, 1000 , and $140 \mu \mathrm{g} / \mathrm{ml}$ with Hill constants equal to 1.8, 2.0, 2.5, 2.0, and 1.4 for the crude, ethanol, acetic acid, aqueous, and acetone extracts, respectively. The acetone extract was the most potent and its $\mathrm{EC}_{50}$ was statistically different (Student $t$-test) from the crude, ethanol, acetic acid, and aqueous extracts $(\mathrm{P}<0.001)$. However, the toxicity of the acetone extract was low, as indicated by the fact that only one (a female) of 10 mice ( 5 males and 5 females) died $24 \mathrm{~h}$ after being injected with the high dose of the acetone extract $(2 \mathrm{~g} / \mathrm{kg})$.

The involvement of the $\beta$-adrenergic, cholinergic or opioid membrane receptors in the mechanism of action of the $C$. sinensis crude extract was also studied ( $\mathrm{N}=3$ atria, 6 trials). None of the above mentioned recep- tors participated (Figure 3), as shown by the fact that none of the following receptor antagonists modified the myocardial effect of the crude extract: $10 \mu \mathrm{M}$ naloxone, $1 \mu \mathrm{M}$ propranolol, or $1.5 \mu \mathrm{M}$ atropine sulfate when added to the bath.

The $C$. sinensis effect on the calcium inward current was also studied by the Nayler and Merrillees protocol (19). This protocol is based on the development of the Bowditch positive staircase phenomenon that is a consequence of an increased calcium entry promoted by a sudden increase of the stimula-

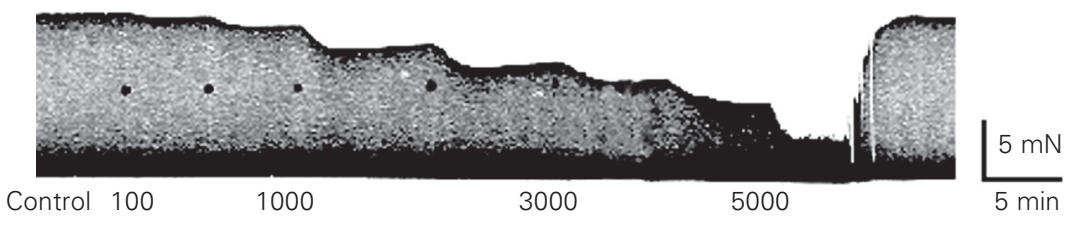

Figure 1. Negative inotropic effect promoted by the crude extract of Citrus sinensis leaves on the guinea pig left atrium. The extract was cumulatively added to the organ bath after a control period and induced a concentration-dependent effect. The atrium was paced at 2 $\mathrm{Hz}$ with pulses of $400 \mathrm{~V}$, and $0.5 \mathrm{~ms}\left(27 \pm 0.1^{\circ} \mathrm{C}\right)$. Similar results were observed in 10 trials carried out on 5 atria. $5 \mathrm{mN}=0.51 \mathrm{gf}$.

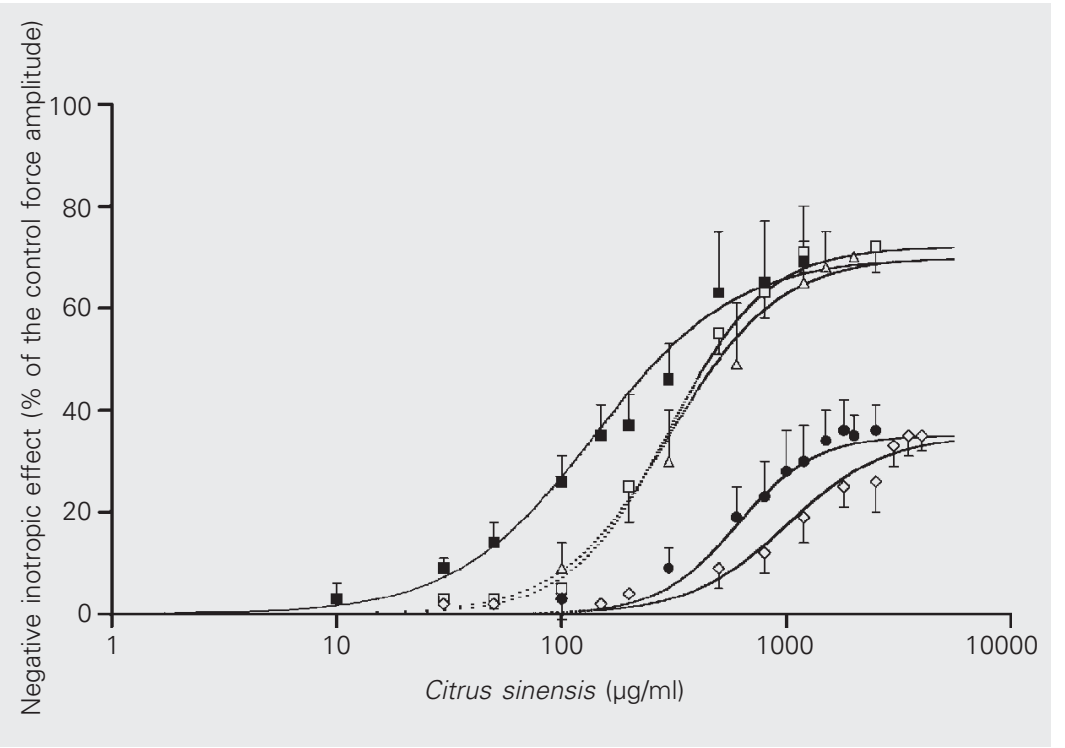

Figure 2. Hill-Langmuir plots constructed to determine the potency of the following Citrus sinesis extracts: acetone (filled squares, $\mathrm{EC}_{50}=140 \mu \mathrm{g} / \mathrm{ml}$, Hill constant $=1.4$ ), ethanol (open squares, $\mathrm{EC}_{50}=300 \mu \mathrm{g} / \mathrm{ml}$, Hill constant $=2$ ), crude (triangles, $\mathrm{EC}_{50}=300 \mu \mathrm{g} / \mathrm{ml}$, Hill constant $=1.8$ ), acetic acid (circles, $E_{50}=600 \mu \mathrm{g} / \mathrm{ml}$, Hill constant $=2.5$ ), and aqueous (lozenges, $\mathrm{EC}_{50}=1000 \mu \mathrm{g} / \mathrm{ml}$, Hill constant $=2$ ). The $\mathrm{EC}_{50}$ of the acetone extract was significantly different from that of all other extracts $(P<0.001)$. The experiments were carried out on electrically paced guinea pig left atria $\left(2 \mathrm{~Hz}, 400 \mathrm{~V}, 0.5 \mathrm{~ms}, 27 \pm 0.1^{\circ} \mathrm{C}, \mathrm{N}=6\right.$ hearts, resting tension: $10 \mathrm{mN}=1.02 \mathrm{gf}$ ). 
Figure 3. The receptor antagonists propranolol $(1 \mu \mathrm{M})$, atropine sulfate $(1.5 \mu \mathrm{M})$, and naloxone $(10 \mu \mathrm{M})$ do not modify the depressor effect produced by the Citrus sinensis crude extract, suggesting that none of them participates in the mechanism of action of this extract on the guinea pig atrium ( $N=3$ atria and 6 trials for each type of receptor studied, $27 \pm 0.1^{\circ} \mathrm{C}$, stimuli: $2 \mathrm{~Hz}, 400 \mathrm{~V}, 0.5 \mathrm{~ms}$ ).

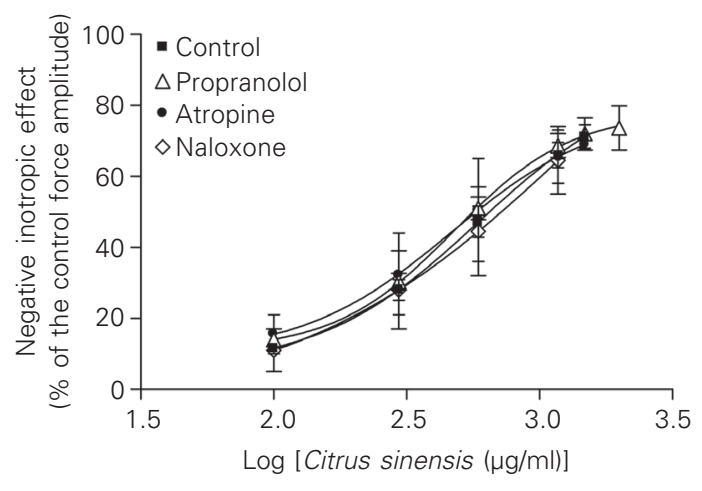

$0.33 \mathrm{~Hz}$
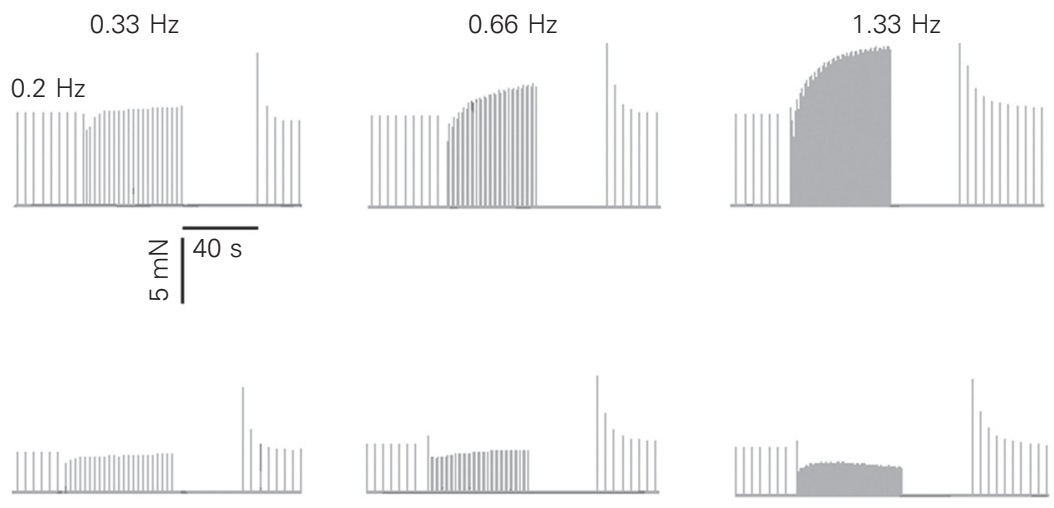

Figure 4. Membrane calcium inward current of isolated atria. The upper panels show the Bowditch positive staircase obtained with the control solution by pacing the atrium at the following rates: $0.33,0.66$, and $1.33 \mathrm{~Hz}$. The data in the bottom panels were obtained with the same stimulation rates but in the presence of the Citrus sinensis acetone extract (1200 $\mu \mathrm{g} / \mathrm{ml})$. In this case, an inverse Bowditch phenomenon occurred (negative force overshoot). Similar results were obtained with 6 other preparations $\left(27 \pm 0.1^{\circ} \mathrm{C}\right.$, control rate: $0.2 \mathrm{~Hz}, 5$ $\mathrm{mN}=0.51 \mathrm{gf})$.

Figure 5. Effect of stimulation frequency on the force overshoot of the guinea pig left atrium. The overshoot is the amount of force that exceeds the control force (control rate: $0.2 \mathrm{~Hz}$ ). Control curve: note that the increase of the stimulation rate led to an increase in force overshoot. When the Citrus sinensis extract $(1200$ $\mu \mathrm{g} / \mathrm{ml}$ ) was added to the bath, the opposite effect was observed. In this case, when the drive frequency was increased, the force overshoot decreased ( $N=6$ hearts, 10 trials, stimulus: $400 \mathrm{~V}$ and 0.5 $\mathrm{ms}, 27 \pm 0.1^{\circ} \mathrm{C}$ ).

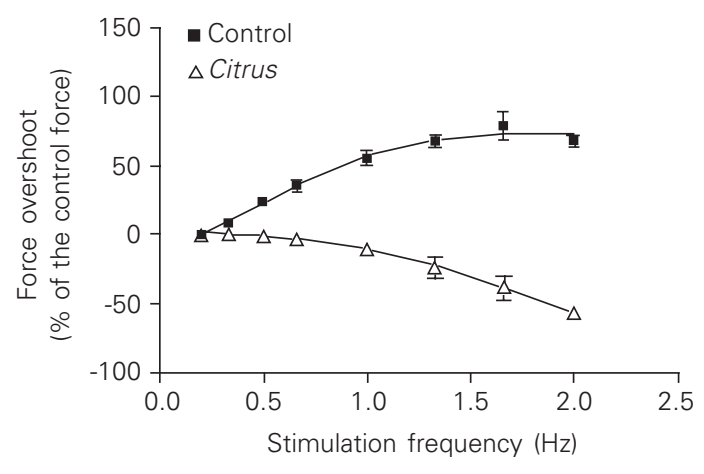

tion rate. Experiments performed at $27 \pm$ $0.1^{\circ} \mathrm{C}$ showed that the force overshoot observed during the positive staircase (Bowditch phenomenon) disappeared when the $C$. sinensis acetone extract $(1200 \mu \mathrm{g} / \mathrm{ml})$ was added to the organ bath (Figure 4). Moreover, the extract was able to induce a frequency-dependent negative staircase phenomenon (Figure 5). Similar results were observed in 6 hearts (10 trials, stimulus: 400 $\mathrm{V}, 0.5 \mathrm{~ms}$ ).

\section{Discussion}

In the present study, we investigated the inotropic effects of some $C$. sinensis leaf extracts on the mammalian myocardium. In the guinea pig atria, these extracts interfered with the atrial contraction mechanism by depressing the myocardial force in a concentration-dependent manner. The crude wateralcohol extract reduced the atrial contractile force with an $\mathrm{EC}_{50}$ equal to $300 \mu \mathrm{g} / \mathrm{ml}$. In the effort to isolate the active crude extract compound, the following water-soluble leaf extracts were obtained: the acetone extract was the most potent $\left(\mathrm{EC}_{50}=140 \mu \mathrm{g} / \mathrm{ml}\right)$ when compared to the ethanol, acetic acid, acetone, and aqueous extracts. The acetone, ethanol, acetic acid, aqueous, and crude extracts exert their myocardial effects by means of a cooperative interaction with the effector site (Hill constant higher than 1). This Hill constant presumably indicates the number of active molecules needed to interact with each binding site in order to promote the biological effect observed (11-13,20).

Neither the cholinergic, nor the opioid or $ß$-adrenergic membrane receptors appear to be involved in the mechanism of action of the crude extracts of $C$. sinensis because atropine sulfate (21), naloxone (22) and propranolol (23) did not change the inotropic response induced by leaf extract.

The disappearance of the Bowditch positive staircase promoted by the acetone extract of $C$. sinensis leaves suggests that the 
extract inhibits membrane calcium inward current. Since the acetone extract of $C$. sinensis induced a negative Bowditch staircase, another mechanism may be acting in parallel to calcium channel inhibition, such as activation of the membrane potassium channels leading to shortening of the action potential.

C. sinensis leaves are known to be rich in flavonoids such as HEPTA, luteolin, apigenin, nobiletin, hesperidin, quercetin, natsudaidain, and diosmin (10). It has been reported that citrus flavonoids can affect cardiac muscle. Quercetin and 3-methylquercitin are substances with a positive chronotropic effect on the right guinea pig atrium (24). Penta- $O$-ethylquercetin induces a rapid and transitory fall in the rat arterial blood pressure mainly due to the inhibition of the cardiac cyclic AMP phosphodiesterase (8). HEPTA flavonoid has a positive inotropic effect on the guinea pig papillary muscle (8). Hesperidin, quercetin, HEPTA, and apigenin - important bioactive substances present in $C$. sinensis leaves - do not seem to be directly involved in the depression of myocardial contractility because their inotropic effect actually corresponded to an increase in the contraction force (25). In contrast, quercetin antagonizes the rate of the spontaneously cytoplasmic calcium oscillation (26), a phenomenon that is known to be related to the calcium-induced calcium release mechanism.

The acetone extract of $C$. sinensis leaves abolished the force overshoot (amount of the force over the force control value), a phenomenon that can be observed when the stimulus rate is suddenly increased (Bowditch phenomenon) for atria maintained in Tyrode solution. This effect indirectly suggests a reduction of the calcium inward current, perhaps by blocking the L-type calcium membrane channels. We observed an inverse relationship between the acetone extract concentration and the force overshoot. Thus, the faster the frequency of stimulation, the more depressed is the force overshoot.

However, it is important to emphasize that since the acetone extract is a mixture of several unknown substances, it cannot be ruled out that we are observing the result of several simultaneous activities. To understand the mechanism underlying these results, we could hypothesize that the extract could also be acting on the membrane potassium conductance. If this is the case, the extract may be opening some potassium channels, contributing to the reduction of the atrial action potential plateau and leading to a decrease of the time interval during which the L-type calcium channels remain open.

In conclusion, we showed that the $C$. sinensis acetone extracts exert a negative inotropic effect and we speculate that they do this by reducing the calcium inward current and by opening some potassium membrane channels. These effects may be clinically relevant because anti-arrhythmic agents usually are myocardial depressant substances.

\section{References}

1. Zohary D \& Hopt M (1993). Domestication of Plants in the Old World: The Origin and Spread of Cultivated Plants in West Asia, Europe, and the Nile Valley. 2nd edn. Oxford University Press, Oxford, England.

2. Janick J, Schery RW, Woods FW \& Ruttan VW (1981). Plant Science: An Introduction to World Crops. 3rd edn. W.H. Freeman and Company, San Francisco, CA, USA.

3. Spiegel-Roy P \& Goldschmidt E (1996). Biology of Citrus. Cambridge University Press, Cambridge, England.
4. Mwaiko GL (1992). Citrus peel oil extracts as mosquito larvae insecticides. East African Medical Journal, 69: 223-226.

5. Fan Y, Ding Z, Yang L, Xu L \& Li K (1995). A preliminary study on bioactivity of orange and tangerine peel extracts against aphis and mites. Zhongguo ZhongYao ZaZhi, 20: 397-398.

6. Caccioni DR, Guizzardi M, Biondi DM, Renda A \& Ruberto G (1998). Relationship between volatile components of citrus fruit essential oils and antimicrobial action on Penicillium digitatum and Penicillium italicum. International Journal of Food Microbiology, 43: 73-79. 
7. Stange Jr RR, Midland SL, Eckert JW \& Sims JJ (1993). An antifungal compound produced by grapefruit and Valencia orange after wounding of the peel. Journal of Natural Products, 56: 1627-1629.

8. Holdsworth DK (1992). A preliminary study of medicinal plants of Easter Island, South Pacific. International Journal of Pharmacognosy, 30: 27-32.

9. Duke JA (1992). Handbook of Phytochemical Constituents of Gras Herbs and Other Economic Plants. CRC Press, Boca Raton, FL, USA.

10. Gil-Izquierdo A, Gil MI, Ferreres F \& Tomás-Barberán FA (2001). In vitro availability of flavonoids and other phenolics in orange. Journal of Agricultural and Food Chemistry, 49: 1035-1041.

11. Nicol KJ \& Chandler BV (1978). Roots as a probable site for citrus limonoid biosynthesis. International Citrus Congress, Sydney, Australia. International Society of Citriculture, 1: 40-42.

12. Stewart I (1985). Identification of caffeine in citrus flowers and leaves. Journal of Agriculture and Food Chemistry, 33: 1163-1165.

13. Itoigawa M, Takeya K \& Furukawa H (1994). Cardiotonic flavonoids from Citrus plants (Rutaceae). Biological and Pharmaceutical Bulletin, 17: 1519-1521.

14. Canecchio Filho V (1979). Administração Agrícola. 5th edn. Instituto Campineiro de Ensino Agrícola, Campinas, SP, Brazil.

15. Domínguez XA (1973). Métodos de Investigación Fitoquímica. Vol. 1. Editorial Limusa, México, DF, México.

16. Voet V, Voet JG \& Pratt CW (2000). Fundamentos de Bioquímica. ARTMED Editora, Porto Alegre, RS, Brazil.

17. Volkenshtein MV (1983). Biophysics. Mir Publishers, Moscow, Russia.

18. Rang HP \& Dale MM (1994). Farmacologia. Guanabara Koogan, Rio de Janeiro, RJ, Brazil.

19. Nayler WG \& Merrillees NCR (1971). Cellular exchange of calcium. In: Harris P \& Opie L (Editors), Calcium and the Heart. Academic Press, New York.

20. Mahler HR \& Cordes EH (1971). Biological Chemistry. 2nd edn. Harper \& Row Publishers, New York.

21. Mehrotra M, Tripathi ON \& Dhawan BN (1985). Mechanism of inhibitory effect of calcium on negative inotropic activity of acetylcholine in guinea pig atria. Biomedica Biochimica Acta, 44: 785-793.

22. Cao CM, Xia Q, Chen YY, Zhang X \& Shen YL (2002). Opioid receptor-mediated effects of interleukin-2 on the $\left(\mathrm{Ca}^{2+}\right)_{i}$ transient and contraction in isolated ventricular myocytes of the rat. Pflügers Archiv. European Journal of Physiology, 443: 635-642.

23. Blin N, Nahmias C, Drumare MF \& Strosberg AD (1994). Mediation of most atypical effects by species homologues of the beta 3adrenoceptor. British Journal of Pharmacology, 112: 911-919.

24. Itoigawa M, Takeya K, Ito C \& Furukawa H (1999). Structure-activity relationship of cardiotonic flavonoids in guinea-pig papillary muscle. Journal of Ethnopharmacology, 65: 267-272.

25. Pyle WG, Smith TD \& Hofmann PA (2000). Cardioprotection with kappa-opioid receptor stimulation is associated with a slowing of cross-bridge cycling. American Journal of Physiology, 279: H1941H1948.

26. Wang Y, Wang HG, Yuan ZK, Zhao XN, Wang JX \& Zhang XZ (1999). Quercitin decreased heart rate and cardiomyocyte $\mathrm{Ca}^{2+}$ oscillation frequency in rats and prevented cardiac hypertrophy in mice. Zhongguo Yaoli Xuebao. Acta Pharmacologica Sinica, 20: 426-430. 